This is an author produced version of a paper published in Biofuels, bioproducts \& biorefining.

This paper has been peer-reviewed but may not include the final publisher proof-corrections or pagination.

Citation for the published paper:

Serina Ahlgren, Anna Björklund, Anna Ekman, Hanna Karlsson, Johanna

Berlin, Pål Börjesson, Tomas Ekvall, Göran Finnveden, Matty Janssen, Ingrid Strid. (2015) Review of methodological choices in LCA of biorefinery systems - key issues and recommendations. Biofuels, bioproducts \& biorefining. Volume: 9, Number: 5, pp 606-619.

http://dx.doi.org/10.1002/bbb.1563.

Access to the published version may require journal subscription.

Published with permission from: John Wiley \& Sons.

Standard set statement from the publisher:

This is the accepted version of the following article: Ahlgren, S., Björklund, A., Ekman, A., Karlsson, H., Berlin, J., Börjesson, P., Ekvall, T., Finnveden, G., Janssen, M. and Strid, I. (2015), Review of methodological choices in LCA of biorefinery systems - key issues and recommendations. Biofuels, Bioprod. Bioref., 9: 606-619., which has been published in final form at http://onlinelibrary.wiley.com/doi/10.1002/bbb.1563/abstract .

Epsilon Open Archive http://epsilon.slu.se 


\title{
Review of methodological choices in LCA of biorefinery systems - key issues and recommendations
}

\author{
Serina Ahlgren ${ }^{1}$, Anna Björklund ${ }^{2}$, Anna Ekman ${ }^{3,7}$, Hanna Karlsson ${ }^{1}$, Johanna Berlin ${ }^{4}$, Pål \\ Börjesson $^{3}$, Tomas Ekvall ${ }^{5}$, Göran Finnveden ${ }^{2}$, Matty Janssen ${ }^{6}$, Ingrid Strid ${ }^{1}$ \\ ${ }^{1}$ Swedish University of Agricultural Sciences, Department of Energy and Technology, Uppsala, Sweden \\ ${ }^{2}$ KTH Royal Institute of Technology, Division of Environmental Strategies Research, Stockholm, Sweden \\ ${ }^{3}$ Lund University, Environmental and Energy System Studies, Department of Technology and Society, Lund, \\ Sweden \\ ${ }^{4}$ SP Technical Research Institute of Sweden, Department of Energy Technology, Gothenburg, Sweden \\ ${ }^{5}$ IVL Swedish Environmental Research Institute, Gothenburg, Sweden \\ ${ }^{6}$ Chalmers University of Technology, Department of Energy and Environment, Gothenburg, Sweden \\ ${ }^{7}$ SIK Swedish Institute for Food and Biotechnology, Sustainable Food Production, Lund, Sweden
}

Correspondence to: Serina Ahlgren, Department of Energy and Technology, Swedish University of Agricultural Sciences, PO Box 7032, S-750 07 Uppsala, Sweden. Email: serina.ahlgren@slu.se, Fax: +4618673156,

Telephone: +4618671294

\begin{abstract}
The current trend in biomass conversion technologies is towards more efficient utilization of biomass feedstock in multi-product biorefineries. Many life cycle assessment (LCA) studies of biorefinery systems have been performed, but differ in how they use the LCA methodology. Based on a review of existing LCA standards and guidelines, this paper provides recommendations on how to handle key methodological issues when performing LCA studies of biorefinery systems. Six key issues were identified: (1) goal definition, (2) functional unit, (3) allocation of biorefinery outputs, (4) allocation of biomass feedstock, (5) land use, and (6) biogenic carbon and timing of emissions. Many of the standards and guidelines reviewed here provide only general methodological recommendations. Some make more specific methodological recommendations, but these often differ between standards. In this paper we present some clarifications (e.g. examples of research questions and suitable functional units) and methodological recommendations (e.g. on allocation).
\end{abstract}

Keywords: Biorefinery; Life cycle assessment; Functional unit; Allocation; Land use;

Biogenic carbon; Review 


\section{INTRODUCTION}

A current trend in biomass conversion technologies is towards more efficient utilization of biomass feedstock in biorefineries (BRs), where products such as food, feed, bioenergy (power, heat, and biofuels for transport), and bio-based products (chemicals, materials) can be produced together. Such synergetic production can allow for high efficiency in terms of economics, energy, resource use, etc. Attempts have been made to distinguish BRs from other biomass-processing industries, such as conventional biofuel plants, food industries, or chemical industries. Berntsson et al. ${ }^{1}$ provide an extensive overview of different definitions of BR. This paper uses the terms "biorefinery" and "biorefinery system" synonymously for all types of BR, and include the biomass processing facilities themselves, but also the biomass feedstock supply system and market for output products.

Life cycle assessment (LCA) is a commonly used method to assess the environmental impact of systems and products. Many LCAs of BR systems have been performed recently, however a literature review published in the background report of this paper reveal that the studies vary widely in how they apply the LCA methodology, leading to inconsistency among studies and poor comparability. ${ }^{2,3}$ Therefore clarification and recommendations on key issues related to LCA of BR systems are required. There is an extensive scientific literature dealing with general LCA methodology, and there exist several LCA standards and guidelines, some specific for bioenergy (Table 1). There is also some literature on LCA methodology for BR

systems. ${ }^{4,5,6,7,8}$ However, none of these previous studies provides systematic methodological recommendations for key LCA issues of BR systems. Moreover, a comprehensive review of BR related key issues and recommendations in existing standards and guidelines is currently lacking. 


\subsection{Aim}

This study reviewed existing LCA standards and guidelines in order to identify and assess key methodological issues for LCA of BR systems. The aim was to reveal the complexities when performing LCA of BR systems and provide insights useful for LCA practitioners within e.g., research, industry, and policymaking. Similarities and differences between the methodological recommendations relating to BR systems given in existing LCA standards and guidelines were identified and discussed. A further aim was to provide methodological recommendations, where possible, on how to handle these critical key issues. Such recommendations can improve the consistency and comparability of future case studies and increase the credibility of the results.

\subsection{Delimitations}

The focus was on key methodological issues that need to be resolved when performing LCA of products from BR systems, although it is not always possible to give BR-specific recommendations without discussing general LCA issues. Issues related to the collection and selection of numerical data in the inventory were excluded. The study was limited to methodological choices connected to the impact categories energy and climate, however characterization methods as such were not addressed. This delimitation restricted the number of key issues, since including e.g., biodiversity or social impacts would raise other methodological questions. A European perspective was adopted, i.e., some EU regulations were included. International standards applicable in an EU perspective were also included.

A base of comparison would be to look at equivalent fossil refineries and how they have handled LCA-issue. However, a previous literature review on this topic ${ }^{9}$ reveals that $^{-1}$ conventional fossil refinery LCA-studies are scarce, and the ones that do exist are not very transparent regarding methodological choices. Most remaining studies that could be useful to 
discuss, all use the same functional unit, same allocation method (physical) and same system boundaries. Therefore there is a very limited amount of references to fossil refinery studies.

\section{Method}

Existing standards and guidelines relevant for LCA of BR systems were reviewed (Table 1). Based on the review and discussions in the project group, six key issues for LCA of BR systems were identified. These key issues were then described and analyzed in order to make methodological recommendations. In the following sections, each key issue is introduced, its importance is explained, and a summary is made of what existing standards and guidelines say about it, with a discussion of any discrepancies in the recommendations. Each key issue is then clarified and recommendations are made on how it can be handled in LCA studies of BR systems. A more detailed description of the key issues is provided in the background report of this paper. ${ }^{3}$ Note that drawing up recommendations always involves a certain measure of subjectivity, so those given here should not be seen as a universal truth, but rather a reflection of the authors' considered opinion. In the background report, a calculation example of a BR system is also presented, showing the influence of some of the discussed key issues.

\section{$3 \quad$ Key issues}

\subsection{Key issue 1: Goal definition}

Goal definition is a key issue since it determines several of the methodological choices that need to be made throughout an LCA. Clear initial goal definition is also essential for correct interpretation of the results. ${ }^{12}$ 


\subsubsection{Review of key issue in standards and guidelines}

According to ISO 14040 and ISO 14044, the goal should state the intended application, reason for the study, intended audience, and whether the results will be used in comparative statements disclosed to the public. While several existing standards and guidelines emphasize the importance of goal definition for methodological choices, they give little or no guidance on this connection. An exception is the GHG Protocol, which is intended to assist companies in performing a GHG inventory of their products, and therefore only allows for attributional accounting. According to Zamagni et al. ${ }^{22}$ attributional LCA (ALCA) accounts for immediate physical flows in a life cycle, while consequential LCA (CLCA) examines the environmental consequences of change in a life cycle, often with a market-oriented approach. Another exception is the ILCD Handbook ${ }^{12}$, which links possible aims/applications or decision situations to methodological mode (attributional or consequential). The ILCD Handbook identifies three "goal situations":

- A: Micro-level decisions (products) $\rightarrow$ ALCA

- B: Meso-macro level decisions (policy) $\rightarrow$ CLCA

- C: Accounting (products and policy)

$\circ \mathrm{C} 1$ : Including interactions with other systems $\rightarrow$ ALCA

$\circ$ C2: Excluding interactions with other systems $\rightarrow$ ALCA

\subsubsection{Discussion and recommendations}

An important part of goal definition is formulation of relevant research questions. Not all types of research question can be answered by performing an LCA of a BR system. In Table 2 we have listed a number of plausible research question for BR LCA-studies. Note that it is not possible to list all possible research questions, and also that the research questions we put down are rather simple. A research question can be more detailed and sophisticated like "What kind of feedstock shall be used for this specific BR and how will this choice impact the regional and global supply of products and how will this effect global land use change". 
However, Table 2 gives an indication of the type of BR-related questions that can be answered with LCA methodology.

All questions listed in Table 2 are of a traditional LCA type, i.e., are static, linear, usually based on historic data, and limited to environmental aspects. Attempts have been made to develop LCA in other directions, e.g., to be dynamic, non-linear, reflect future performance, and include social and economic aspects. ${ }^{23,24}$ In that case, other types of questions can become relevant, e.g.:

- When should a BR be built?

- What production capacity should a BR have?

- How sustainable is the BR or a specific BR product compared with other products?

The choice of LCA approach (ALCA or CLCA) is closely connected to the research question. Despite the claims made in the ILCD Handbook, choice of ALCA or CLCA is not always straight-forward. For example, what appear to be small changes in question formulation can change an ALCA into a CLCA, and vice versa. Due to the difficulties in classifying research questions as ALCA or CLCA, we recommend that practitioners describe the research question, but also state and justify why they intend to use ALCA or CLCA. The choice of LCA approach should be carefully considered for each specific study, particularly as regards whether the methodological choices made can supply meaningful answers to the research questions.

In goal formulation, it is also important to specify the time horizon of the study. Note that there are several different time horizons in an LCA: how long the results can be used as a basis for decisions (typically 1-10 years), how far into the future analysis of the sociotechnical system extends (typically 10-100 years for different parts of the system), the time 
horizon used to calculate emissions from landfills (often 100 years after deposition), the climate impact of greenhouse gases (often 100 years after emission), etc. Ideally, all these time horizons should be specified in the goal and scope definition.

\subsection{Key issue 2: Functional unit}

Choice and formulation of functional unit is identified as a key aspect in several publications $^{25}$, and is important with regard to both the comparability and the interpretation of results. ${ }^{26}$ The choice of functional unit is particularly important for BRs, since by definition they produce more than one product and it may be difficult to identify one main function. ${ }^{27}$

\subsubsection{Review of key issue in standards and guidelines}

ISO 14040 and ISO 14044 list general requirements on the functional unit and state that it should be consistent with the goal of the study. The ILCD Handbook specifies some concrete requirements and optional procedures for choosing the functional unit, such as identifying all the functions of the production system studied. PEF and OEF give guidance on how the functional unit should be formulated (e.g., by defining it according to the aspects "what", "how much", how well”, and "how long”). The GHG Protocol also gives guidance on selection of functional unit and several examples. However, no existing standard or guideline links choice of functional unit to goal definition or any other methodological choice.

Some environmental declaration standards state the functional unit. For example, in the RED the functional unit is always $1 \mathrm{MJ}$ of fuel and in PCR for basic organic chemicals the functional unit is $1000 \mathrm{~kg}$ of packaged product ready for delivery. However, this is of little help for BRs, where there are always two or more products. 


\subsubsection{Discussion and recommendations}

Although some authors call for a harmonization of functional units for the sake of comparability of results ${ }^{28}$, it is important to realize that the functional unit is closely related to the study aim. Thus, depending on the research question, different types of functional units will be suitable. Here we have identified four different categories of functional units (Table 2). For each category we give some examples of functional units and research questions.

The input based functional unit category "use of feedstock" is suitable for determining the best use of land or biomass, considering that these are limited resources. It can also be useful when analyzing different ways of handling waste.

If the aim is to compare the products of a BR, the products themselves or the function of the products can be used as the functional unit. In a strict interpretation of the ISO-standard, the function of the products is the appropriate unit. For example when comparing biofuels 1 person-km can be a good choice since fuels have different engine conversion efficiencies; simply comparing $1 \mathrm{MJ}$ of fuels would not reflect the diversity of the fuels. A product based functional unit can be useful in some cases, for example when communicating results to end users, such as environmental labeling of products.

BRs produce several useful products, meaning that selection of one main product may be difficult. Using several functions (e.g., a combination of output products or $1 \mathrm{BR}$ ) as the functional unit is rather common ${ }^{2}$, and may be very useful when identifying hotspots, comparing supply of the same functions based on fossil fuels, or comparing stand-alone plants with integrated systems (i.e., BRs). However it may be a disadvantage in some situations, not least when communicating results to consumers, industry etc. For example, it can be difficult 
for a consumer or producer to interpret and make informed decisions if the results are expressed as kg global warming potential per " $1 \mathrm{MJ}$ ethanol, $1 \mathrm{~kg}$ bio-plastic, and $1 \mathrm{MJ}$ electricity". Further, the aggregated results have a limited ability to be compared with other studies; often one is interested in one of the products, e.g. when comparing different biofuels.

To conclude, it is important to choose a functional unit compatible with the aim of the study. Sometimes a study can have multiple aims; in this case different functional units can be used to fulfill the aim. It is however important to highlight which functional unit addresses which aim.

\subsection{Key issue 3: Allocation of biorefinery outputs}

A so-called multifunctionality (or allocation) problem arises when two (or more) products share or partly share a production system. A BR always produces more than one valuable output, and the choice of method to deal with multifunctionality in BR systems will have a strong influence on the results. Furthermore, the output products from a BR can have different functions and physical attributes, e.g., the function of products can be heating, nutritional, pharmaceutical, packaging, etc., making it difficult to decide on one appropriate allocation basis. This is discussed in several previous publications. ${ }^{\text {7,29 }}$

In some cases, the classification (or consideration ${ }^{30}$ ) into product, co-product, by-product, waste, and residue can be very important for choice of allocation basis. For example, in the RED a by-product should be allocated emissions, while a waste product should not. These different classifications are described in full in the background report of this paper. ${ }^{3}$ 


\subsubsection{Review of key issue in standards and guidelines}

According to ISO 14040 and ISO 14044, allocation (partitioning) should be avoided if possible, firstly by increasing the level of detail in the modelling (identifying product-specific flows) and secondly by system expansion (see below). If allocation cannot be avoided, ISO 14040 and ISO 14044 recommend allocation based on underlying physical relationships, or on other characteristics such as economic value.

The ILCD Handbook roughly follows the method hierarchy of the ISO standards, but uses the three different types of goal situations (see Key issue 1) as the basis for its guidance regarding allocation choices. For situations A, B and C1, it recommends that system expansion be used, or otherwise allocation may be used. For situation $\mathrm{C} 2$, it recommends that multifunctionality be solved with allocation.

The PEF guide is in accordance with ISO, but gives specific examples. For example, system expansion should only be applied if a direct substitution effect can be robustly modelled. PCR for basic organic chemicals do not allow system expansion, but are otherwise in accordance with the ISO standards. However, the RED requires allocation by partitioning, based on the lower heating value (LHV) of the products, except for excess electricity which is treated with system expansion. According to the GHG Protocol, companies should avoid allocation wherever possible by using process subdivision or redefining the functional unit; system expansion may only be used in a separate report.

\subsubsection{Discussion and recommendations}

In existing standards and guidelines, recommendations on how to handle multifunctionality differ and there is a lack of definition of different methods to deal with multifunctionality. 
Therefore it can be helpful to review the different methods for solving multifunctionality before giving recommendations.

\section{Avoiding allocation by increasing the level of detail}

A multifunctional process sometimes comprises several sub-processes, each with a single functional output. In such cases, allocation can be avoided through an increased level of detail in modelling within the inventory analysis. In this detailed model, each product is ascribed emissions only from the sub-processes involved in production of that specific product. However, this is often not possible in practice, due to lack of detailed data. Moreover, many processes are impossible to divide into sub-processes. Therefore allocation situations might not be eliminated by increasing the level of detail. Even when a multifunctional process can be completely divided into single functional sub-processes, these typically depend on each other, e.g., to be economically viable. ${ }^{31}$ For this reason, the method is often unsuitable for CLCA.

\section{Avoiding allocation by system expansion}

There are two forms of system expansion: substitution and enlargement. These have many similarities and are often confused. The methods are mathematically equivalent, but not necessarily equal in meaning and interpretation, as they do not study the same functions (Figure 1). ${ }^{12,32}$

When substitution is applied in an LCA that includes the main product of the BR, the environmental burden is calculated as the emissions from the BR minus the avoided emissions from the avoided production of the products displaced by the BR co-products.

In comparative studies, system boundaries can be expanded so that the systems compared encompass the same multiple functions. This type of system expansion is called system 
enlargement according to the ILCD Handbook. However, applying system enlargement does not solve the original multifunctionality problem that arises with several output products from the BR, but simply changes the functional unit and the reference flow. Consequently, the LCA answers a different question. In fact, ISO 14044 describes this method of enlargement in a section on function and functional units. This approach is suitable when comparing only a few systems. With an increasing number of systems, it is increasingly difficult to define relevant systems producing the same output or function. ${ }^{33}$

Both types of system expansion have a clear advantage; if products with different applications and features are produced, it can be difficult to perform a physical allocation (image for example a BR were biofuel, antibiotics and district heating is produced). System expansion does not need to consider this, since only the use of the by-products in other systems are studied, independent of it's physical character.

One of the main challenges when performing system expansion is the high uncertainty concerning which product systems are affected by changes in the system under study. ${ }^{35}$ Besides this, only a certain amount of products can be substituted before a market is saturated. The substitution is therefore only valid to a certain threshold. For some studies this imposes little trouble, for others, i.e. when studying larger societal transitions, this is of major importance. ${ }^{36}$

While many authors argue that system expansion is suitable only in CLCA ${ }^{25,37}$, Finnveden et al. ${ }^{38}$ claim that it can be applied in ALCA if the LCA concept is interpreted as a tool for investigating not only individual life cycles, but also combinations of life cycles. The ILCD Handbook states that substitution is applicable for ALCA, but only in situation C1. 


\section{Allocation}

Allocation can be based on underlying physical relationships, or other relationships such as economic value. ISO 14044 states that:

“a) Where allocation cannot be avoided, the inputs and outputs of the system should be partitioned between its different products or functions in a way that reflects the underlying physical relationships between them.

b) Where physical relationship cannot be established or used as the basis for allocation, the inputs should be allocated between the products and functions in a way that reflects other relationships between them. For example, input and output data might be allocated between co-products in proportion to the economic value of the products."

One interpretation of case (a) is that it includes processes where the ratio of the output products is not fixed, but can be changed according to what the producer deems most suitable. This means that in theory, it should be possible to establish a causal relationship between a change in each individual output product and the related change in emissions. This relationship can be expressed in mathematical terms to form the basis for allocation of emissions between different products.

When the ratio between output products cannot be changed, however, and a change in the output of one product by necessity leads to a corresponding change in the output of the other products, there is no underlying physical relationship between this product and the emissions on which to base allocation, resulting in case (b). The classic example is the production of chlorine and $\mathrm{NaOH}$ through electrolysis. Their relative proportions are decided by the chemical stoichiometrics of the reaction, and the output ratio cannot be changed. 
For case (b), other relationships can be used as the basis for allocation. For BRs producing a diverse set of products, it can be difficult to find a common criterion that is appropriate as an allocation basis. For example, mass-based allocation can be useful in some cases, but the mass of a substance does not reflect the composition of a product; $1 \mathrm{~kg}$ of wood bark would be treated exactly as $1 \mathrm{~kg}$ of ethanol. ${ }^{7}$ Allocation based on energy can also be problematic to justify, since not all co-products are produced for energy purposes. ${ }^{6,39}$ Furthermore, using LHV as the basis for allocation (the RED method) can be problematic, since wet materials, heat and steam have very low and sometimes even negative LHV. Some of these issues can be resolved by using exergy as the basis for allocation but this has limitations, e.g., the practical utility of products (e.g., plastics or wood products) is overlooked. ${ }^{7}$ Allocation based on economic value could be problematic due to price fluctuations, subsidies, etc. ${ }^{40}$ However, economic profit from a system is one of the reasons it exists, and expected revenue has been proposed as a basis for allocation, since it fluctuates less over time than actual prices. ${ }^{41}$

When modelling a change in demand, as in CLCA, the distinction between cases (a) and (b) is also important. In case (a), a change in demand for a product might lead to a change in the combination of output products. In case (b), when the output of the co-products cannot be independently varied, a change in demand for one co-product will lead to a corresponding change in the total production volume of the BR. The issue of co-products in CLCA is described in detail elsewhere, e.g., Weidema et al. ${ }^{42}$

A hybrid approach were system expansion and allocation is mixed, has been proposed for use in BR case studies. ${ }^{6,43}$ In this approach the allocation is based on the environmental reduction potential of the replaced functions. Depending on the particular goal of the study, different 
environmental impact categories can be used (e.g. toxicological impacts, acidification, primary energy consumption) as the basis for the allocation factors. The method is untested and the authors recommended it to be used in sensitivity analysis as a complementary to other more traditional ways of handling multifunctionality. ${ }^{43}$

\section{Recommendations}

Based on above discussion, the following order of priority in handling multifunctionality in BR systems can be recommended:

- Avoid allocation by increasing the level of detail with a sub-process approach (applicable mainly for ALCA)

- Avoid allocation by system expansion using substitution or system enlargement (applicable mainly for CLCA)

- Allocate based on the physical relationship between products if possible, or on a reasonable approximation of the physical relationship (applicable mainly for ALCA)

- Allocate based on other relationship between products, as first choice we recommend expected revenue as the basis for allocation (applicable mainly for ALCA).

There could be several reasons to diverge from this list of priorities. For example, system enlargement can be applicable in ALCA if the study is interpreted as analyzing not a single life cycle, but a combination of life cycles. Allocation based on physical relationships or other relationships is applicable when it is difficult to identify realistic substitutes for the coproducts and when the allocation problem is not significant for the conclusions of the study. It could also be a good idea to test different methods of handling multifunctionality or assumptions of data in the sensitivity analysis, to see if the allocation problem can affect the conclusions of the study.

\subsection{Key issue 4: Allocation of biomass feedstock}

Including the environmental impact of cultivation of a dedicated energy crop that does not yield any residues should be fairly straight-forward, at least in ALCA. ${ }^{44}$ However agriculture or forestry biomass production systems often yield more than one product. Also, different 
wastes, residues, or co-products can be used as BR feedstock. This multifunctionality of the feedstock-producing system is an important key issue in LCA of BR systems, because the choice of allocation procedure may have a significant influence on the burdens allocated to the BR feedstock.

\subsubsection{Summary of key issue in standards and guidelines}

Several of the standards and guidelines reviewed, e.g., the ISO standards and the ILCD Handbook, do not explicitly mention how to handle feedstock originating from multifunctional systems, but in general the recommendations on allocation for multiple output and end-of-life should apply.

The PEF handbook gives special advice on recycled materials. When these are used as feedstock, only conversion of recycled materials should be included in the inventory. From this, it can be concluded that zero burdens should be allocated to recycled materials from previous life cycle stages. The GHG Protocol also gives special advice on allocation due to recycling, distinguishing between closed loop and recycled content method. The RED mentions that wastes and agricultural residues should be considered to have zero life cycle GHG emissions up to the process of collection of those materials.

\subsubsection{Discussion and recommendations}

If BR feedstock origins from a multifunctional system, it can be attributed an environmental impact by use of system expansion or allocation, as recommended in the previous section. Note, however, that in the case of residues from agriculture and forestry there is seldom physical causation; e.g., it is not possible to change the amount of bark produced on a tree. If performing an allocation it has to be based on another relationship between products, as first choice we recommend expected revenue. 
If the removal of residues from agriculture or forestry leads to soil carbon losses, these should be accounted for and allocated fully to the residue, e.g., soil carbon losses due to straw removal should not be allocated to cereal production. If the input to the BR has a negative economic value, i.e., if the BR is paid to accept it (e.g., certain wastes), waste treatment is one of the functions of the BR. In that case, no part of agriculture or forestry should be allocated to the BR products. Instead, the environmental impact of the BR can be allocated between the BR products and the waste treatment.

In a CLCA approach, it is relevant to expand the system by studying alternative uses of the feedstock and the consequences of redirecting this feedstock to the BR. For residue feedstock, the alternative could be to leave it in the field, or to harvest it for another use. For waste feedstock, an alternative fate could be e.g., landfilling or incineration. For a dedicated biorefinery crop, a consequential approach can mean including market-triggered changes in land use, a separate key issue (see below). Furthermore, any co-products or residues can be treated by system expansion.

To sum up; choice of allocation method for biomass input allocation issues should be connected to the aim of the study. It is logic to use the same method for handling multifunctionality for both the inputs and outputs of the BR system. If a mixture of methods is used, this should be clearly stated and justified.

\subsection{Key issue 5: Land use}

By definition, in a BR one or several types of biomass are used as feedstock. Using biomass generally involves some form of land use. A distinction can be made between land use (LU) (or 'land occupation') and land use change (LUC) (or 'land transformation'). ${ }^{45}$ Furthermore, LUC can be divided into two groups: direct land use change (DLUC) and indirect land use 
change (ILUC). Direct changes concern the location of the feedstock production itself, while indirect changes are market-induced effects elsewhere due to the feedstock production system. ILUC occurs when increased demand for a product leads to displacement or intensification of agricultural production. ILUC connected to biofuel production has been heavily debated, with some studies showing that biofuels have a larger climate impact than fossil fuels when emissions from ILUC are taken into account. ${ }^{46}$ Therefore, this is an important key issue in LCA of BR systems.

\subsubsection{Summary of key issue in standards and guidelines}

Direct land use change is not mentioned in ISO 14040 and ISO 14044, but must be accounted for according to most other standards and guidelines, e.g., PAS 2050, ISO/TS 14067, ILCD, and RED. Many standards and guidelines refer to the methodology developed by IPCC for the calculations and emission factors. The GHG Protocol distinguishes separate methodologies for DLUC accounting depending on whether the location of the specific land use is known or unknown. The GHG Protocol generally does not allow for inclusion of ILUC other than in a special report. In the RED, DLUC must be accounted for, but only under certain conditions, e.g., if it takes place on land not classified as farmland in January 2008. Discussions continue on whether ILUC should be included in the RED. ${ }^{47}$ Both the ILCD Handbook and PEF recommend not including ILUC, since there is no methodology available for dealing with such change. ${ }^{48}$

\subsubsection{Discussion and recommendations}

DLUC is included in many existing standard and guidelines. However, there are great uncertainties due to difficulties in establishing the status of land before and after the change and due to uncertainties in quantification of carbon changes, which are variable and sitespecific. Another uncertainty connected with DLUC is how to allocate the impacts over time, 
e.g., the number of years over which the emissions should be distributed after a piece of land is converted from forestry to agriculture (see Key issue 6).

Quantification of environmental impacts due to ILUC is very different from quantification of those due to DLUC, as the theory of ILUC is based on expected market reactions to increasing demand for a product. ILUC is not observable and the only way to quantify it is by using models. Such quantification is commonly based on global or regional economic equilibrium modelling and the results from different studies show large variations. ${ }^{47} \mathrm{~A}$ number of aspects need to be considered when combining economic models with LCA (or adding results from the two types of models); there can be differences in assumptions regarding time, allocation procedures, data collection, etc. There are also some fundamental differences that need to be considered:

- While LCA is process-specific, economic equilibrium models study changes on a regional or global level, after which impacts are allocated over single products. A typical question addressed by an economic ILUC model is: "What is the global land use change due to the implementation of a biofuel policy?"

- While LCA can use an accounting or consequential approach, economic equilibrium models typically have a consequential perspective, looking into future changes of increased demand for a product on the market, modelling marginal effects.

- While LCA models do not optimize, most economic equilibrium models optimize something, often the profit of companies or a welfare function.

Even though DLUC implies a change in land use, it seems logical that this change be included in both attributional and consequential LCA, as occurs within the studied system 
boundary and therefore can be treated as a process emission. If there is a DLUC, we recommend always including this in the study.

An ILUC occurs outside the specific BR system, implying that in principle, ILUC should not be included in an ALCA. The economic models used to quantify ILUC also have much more in common with CLCA, as they study increased demand on a market. Due to the uncertainties in economic modelling, a strict recommendation always to include ILUC cannot be made at present. Examination of this factor in sensitivity analysis is encouraged, however.

\subsection{Key issue 6: Biogenic carbon and timing of emissions}

It is sometimes assumed that the carbon dioxide $\left(\mathrm{CO}_{2}\right)$ from biogenic sources has no climate effect. However, when evaluating the climate benefits of bio-based systems this could be an oversimplification, since there is a time lag between uptake and release of $\mathrm{CO}_{2}$, especially for biomass with long rotation periods. ${ }^{49}$ A specific feature of BRs is that bio-based materials can be produced, so there can be a period of carbon storage in e.g., plastic or woody material. Carbon storage also occurs if some of the BR biogenic waste ends up in a long-term landfill or if carbon capture and storage (CCS) technology is used in the future. Also, as mentioned above, LUC leads to emissions of carbon, which need to be included. All this makes accounting for biogenic carbon and timing of emissions an important key issue in LCA of BR systems.

\subsubsection{Summary of key issue in standards and guidelines}

There are no methodological recommendations in the ISO standards explicitly relating to biogenic carbon. However ISO 14047, which provides examples of impact assessment according to ISO 14044 , treats carbon sequestration as a separate impact category. ${ }^{50}$ 
The ILCD Handbook states that biogenic and fossil $\mathrm{CO}_{2}$ and methane emissions and removals must be reported separately in the inventory results. LUC-related $\mathrm{CO}_{2}$ emissions from soil, peat, etc., in all cases and from biomass and litter of virgin forests must be inventoried as "Carbon dioxide (fossil)". Emissions from biomass and litter of secondary forests must be inventoried as "Carbon dioxide (biogenic)". Uptake of $\mathrm{CO}_{2}$ from the atmosphere and release of biogenic $\mathrm{CO}_{2}$ are both assigned characterization factors for the impact assessment. Temporary carbon storage in e.g., products within the first 100 years from the time of the study should only be considered quantitatively if this is explicitly required to fulfil the goal of the study. The ILCD Handbook provides a method for this, which includes storage of carbon originating from both fossil and biomass sources..

In PEF, biogenic and fossil carbon are reported separately in the inventory and carbon removal from the atmosphere has a characterization factor of $-1 \mathrm{CO}_{2}$-eq. for global warming, while release of biogenic carbon has a characterization factor of $+1 \mathrm{CO}_{2}$-eq. Credits associated with temporary carbon storage or delayed emissions should not be generally considered in the calculation, according to PEF.

PAS states that for food and feed, any emissions and removals arising from biogenic sources that become part of the product may be excluded. However, emissions and removals of biogenic carbon used in the production of food and feed (e.g., in burning biomass for fuel), where that biogenic carbon does not become part of the product, must be accounted for. For storage of carbon in products, PAS suggests a rather complicated framework that has much in common with the framework proposed by the ILCD Handbook. ${ }^{29}$ 
Some of the more specific guidelines also treat the biogenic carbon issue to a certain extent. For example, in PCR for basic organic chemicals, GHG emissions must be reported in two separate categories: (1) Excluding emissions of biogenic $\mathrm{CO}_{2}$ and $\mathrm{CO}_{2}$ sequestration or (2) excluding emissions of biogenic $\mathrm{CO}_{2}$, but including $\mathrm{CO}_{2}$ sequestration. In the RED, emissions of $\mathrm{CO}_{2}$ from the fuel in use must be taken as zero for biofuels and bioliquids. However this is under discussion, especially in relation to the development of sustainability criteria for solid bioenergy. $^{51}$

\subsubsection{Discussion and recommendations}

In general, methodological issues connected to biogenic carbon in LCA of BR systems can be divided into three categories:

- Land use change, emissions or sequestration of biogenic carbon and other GHGs

- Carbon cycle in bioenergy production systems, biomass growth and combustion

- Storage of biogenic carbon in products, wastes, carbon capture and storage, etc.

Some of the standards and guidelines reviewed cover biogenic carbon from land use and storage of carbon in products, but the carbon cycle in bioenergy production systems is generally omitted, i.e., there is no method to capture the timing of emissions or sequestration.

Global warming potential (GWP) using a 100-year time horizon is one of the most commonly used characterization factors for potential climate impact in LCA. Characterization factors are used to convert net emissions of different GHG to a common, unitless indicator value $\left(\mathrm{CO}_{2}\right.$ eq.). This is equivalent to accounting all emissions occurring throughout the study period as occurring in the same year ${ }^{52}$ and thus it cannot capture the timing of emissions. ${ }^{49}$ In order to reflect the climate impacts in relation to the temporal distribution of emissions, other methods are needed. Several approaches have been proposed to account for the timing of emissions and sequestration, in the context of carbon accounting in LCA. ${ }^{49,52}$ 
Furthermore, the discussions on biogenic carbon accounting have raised more questions which are important for LCA, such as differences in accounting method between different types of feedstock (e.g., residues vs. stem wood), stand vs. landscape level, what the reference land use should be, and market effects in the forestry sector. ${ }^{51}$ In view of this, it is not easy to provide recommendations on how biogenic carbon and timing of emissions should be handled in LCA of BR systems at the moment. However, a few conclusions can be drawn:

- Timing of emissions is usually not included in LCA of BRs. However, if there are significant differences in time between $\mathrm{CO}_{2}$ uptake and emissions from the system under study, this should not be ignored. It should at least be discussed in the study and efforts made to quantify the impact. Note that the commonly used GWP metric has certain limitations regarding its ability to reflect timing of emissions, e.g., to reflect the time lag between sequestration of $\mathrm{CO}_{2}$ in forest biomass and the point of combustion. At this point, the GWP is more or less standardized and it is difficult to recommend use of any specific alternative metric, however we do advice exploring the options, see e.g. ${ }^{49,52,53,54}$

- For the special case of delayed emissions due to storage of biogenic and fossil carbon in products, landfill, and carbon capture and storage, PAS and the ILCD Handbook have developed calculation methods, which can be incorporated within existing LCA methodology and the GWP metric.

\section{Conclusions}

This study reviewed existing LCA standards and guidelines and identified and clarified key methodological issues for LCA of BR systems. It was found that many of these standards and 
guidelines provide general methodological recommendations and some provide more specific recommendations, but these often differ between standards.

Based on the analysis, we provide some methodological recommendations on how to handle the key issues identified. Discussions on BR systems and how they can be evaluated have raised many questions important for LCA, including BR-specific, biomass-specific, and general LCA issues. For example, allocation problems are general for all LCA studies, and recommendations should be compatible with all product groups, so that e.g., BR-specific solutions are avoided. Studying biorefinery systems also highlights the need for more method development, e.g., on how to handle biogenic carbon. The present analysis focused on six key issues, but several other issues that need to be dealt with when performing LCA of BRs were not covered, e.g., choice of data, market restrictions of co-products, choice of reference system. Furthermore, the present analysis focused on energy- and GHG emission-related key issues, but there are many other sustainability issues connected to BR systems, e.g., soil degradation, water use and biodiversity.

\section{Acknowledgement}

The authors kindly acknowledge The Swedish Knowledge Center for Renewable Transport Fuels (the f3 center) for financial support.

\section{References}

1. Berntsson T, Sandén B, Olsson L and Åsblad A, What is a biorefinery? In: Systems perspectives on biorefineries, ed by Sandén, B and Pettersson, K, Chalmers University of Technology, Gothenburg, Sweden (2013).

2. Ahlgren S, Ekman A, Karlsson H and Björklund A, Methodology for LCA of biorefineries - a literature review, The 6th International Conference on Life Cycle Management, Gothenburg, Sweden 25-28 August (2013).

3. Ahlgren S, Björklund A, Ekman A, Karlsson H, Berlin J, Börjesson P, et al., LCA of Biorefineries Identification of Key Issues and Methodological Recommendations. Report No 2013:25, f3 The Swedish Knowledge Centre for Renewable Transportation Fuels, Sweden. Available at http://www.f3centre.se (2013). 
4. Valente C, Saur Modahl I and Askham C, Method development for Life Cycle Sustainability Assessment (LCSA) of New Norwegian Biorefinery. Østfoldforskning, Report no. OR.39.13. ISBN: 82-7520-711-8. Kråkerøy, Norway (2013).

5. Sandén B and Pettersson K (eds), Systems perspectives on biorefineries. Version 2.1. E-published at: http://www.chalmers.se/en/areas-of-advance/energy/cei/Pages/Systems-Perspectives.aspx Chalmers University of Technology, Gothenburg, Sweden [accessed 15 August 2014].

6. Cherubini F, Strømman AH and Ulgiati S, Influence of allocation methods on the environmental performance of biorefinery products--A case study. Resources, Conservation and Recycling 55(11):1070-1077 (2011).

7. De Meester S, Life cycle assessment in biorefineries: case studies and methodological development. Doctoral thesis. Ghent University (2013).

8. Sacramento - Rivero JC, A methodology for evaluating the sustainability of biorefineries: framework and indicators. Biofuels, Bioproducts and Biorefining 6(1):32-44 (2012).

9. Eriksson M and Ahlgren S,LCAs of gasoline and diesel - a literature review. Report 2013:058. Department of Energy and Technology, Swedish University of Agricultural Sciences. Uppsala, Sweden. ISSN 16549406; (2013).

10. International Organization for Standardization, Environmental management - Life cycle assessment Principles and framework (ISO 14040:2006). European Committee for Standardization, Brussels, Belgium (2006).

11. International Organization for Standardization, Environmental management - Life cycle assessment Requirements and guidelines (ISO 14044:2006). European Committee for Standardization, Brussels, Belgium (2006).

12. JRC Joint Research Centre, ILCD Handbook. International Reference Life Cycle Data System. General guide for Life Cycle Assessment - Detailed guidance. First edition (2010).

13. World Resources Institute, Greenhouse Gas Protocol. Product Life Cycle Accounting and Reporting Standard. Washington DC, USA http://www.ghgprotocol.org/standards/product-standard (2011).

14. European Commission, Product environmental footprint (PEF) guide to the Commission recommendation on the use of common methods to measure and communicate the life cycle environmental performance of products and organizations, Annex II (2013).

15. European Commission, Organization environmental footprint (OEF) guide to the Commission recommendation on the use of common methods to measure and communicate the life cycle environmental performance of products and organizations, Annex III (2013).

16. International Organization for Standardization, ISO 14025:2006, Environmental labels and declarations -Type III environmental declarations - Principles and procedures. European Committee for Standardization, Brussels, Belgium (2006).

17. The International EPD®system, Product category rules (PCR) for preparing an environmental product declaration (EPD) for CPC division 341, Basic organic chemicals, PCR 2011:17 VERSION 1.1. (2013).

18. European Commission, Directive 2009/28/EC of the European Parliament and of the Council of 23 April 2009 on the promotion of the use of energy from renewable sources and amending and subsequently repealing Directives 2001/77/EC and 2003/30/EC. COD(2008)0016 (2009).

19. European Committee for Standardization, EN 16214-4: Sustainably produced biomass for energy applications - Principles, criteria, indicators and verifiers for biofuels and bioliquids - Part 4: Calculation methods of the greenhouse gas emission balance using a life cycle analysis (2013).

20. International Organization for Standardization, ISO/TS 14067:2013. Greenhouse gases - Carbon footprint of products -- Requirements and guidelines for quantification and communication (2013).

21. British Standards, Specification for the assessment of the life cycle greenhouse gas emissions of goods and services. PAS 2050:2008. Publicly Available Specification (2011).

22. Zamagni A, Guinée J, Heijungs R, Masoni P and Raggi A, Lights and shadows in consequential LCA. The International Journal of Life Cycle Assessment 17(7):904-918 (2012).

23. Ekvall T, Assefa G, Björklund A, Eriksson O and Finnveden G, What life-cycle assessment does and does not do in assessments of waste management. Waste Management 27(8):989-996 (2007).

24. Guinée JB, Heijungs R, Huppes G, Zamagni A, Masoni P, Buonamici R, et al., Life Cycle Assessment: Past, Present, and Future $\uparrow$. Environmental Science \& Technology 45(1):90-96 (2010).

25. Iswanto Wiloso E and Heijungs R, Key Issues in Conducting Life Cycle Assessment of Bio-Based Renewable Energy Sources. In: Life Cycle Assessment of Renewable Energy Sources, ed by Singh A, Pant D and Olsen SI, Springer, London, pp 13-36 (2013).

26. Cherubini F and Strømman AH, Life cycle assessment of bioenergy systems: State of the art and future challenges. Bioresour. Technol. 102(2):437-451 (2011).

27. Parajuli R, Dalgaard T, Jørgensen U, Adamsen APS, Knudsen MT, Birkved M, et al., Biorefining in the prevailing energy and materials crisis: a review of sustainable pathways for biorefinery value chains 
and sustainability assessment methodologies. Renewable and Sustainable Energy Reviews 43(0):244263 (2015).

28. Kajaste R, Chemicals from biomass - managing greenhouse gas emissions in biorefinery production chains a review. Journal of Cleaner Production 75(0):1-10 (2014).

29. Pawelzik P, Carus M, Hotchkiss J, Narayan R, Selke S, Wellisch M, et al., Critical aspects in the life cycle assessment (LCA) of bio-based materials. Reviewing methodologies and deriving recommendations. Resources, Conservation and Recycling 73(211-228 (2013).

30. Heimersson S, Morgan-Sagastume F, Peters GM, Werker A and Svanström M, Methodological issues in life cycle assessment of mixed-culture polyhydroxyalkanoate production utilising waste as feedstock. New Biotechnology 31(4):383-393 (2014).

31. Ekvall T and Finnveden G, Allocation in ISO 14041 - a critical review. Journal of Cleaner Production 9(3):197-208 (2001).

32. Heijungs R and Guinée JB, Allocation and 'what-if' scenarios in life cycle assessment of waste management systems. Waste Management 27(8):997-1005 (2007).

33. Pettersson K and Grahn M, How much can biofuels reduce greenhouse gas emissions? In: Systems perspectives on biorefineries, eds by Sandén B and Pettersson K, Chalmers University of Technology, Gothenburg, Sweden (2013).

34. Finnveden G, Methodological aspects of life cycle assessment of integrated solid waste management systems. Resources, Conservation and Recycling 26(3-4):173-187 (1999).

35. Gnansounou E, Dauriat A, Villegas J and Panichelli L, Life cycle assessment of biofuels: Energy and greenhouse gas balances. Bioresour. Technol. 100(21):4919-4930 (2009).

36. Weidema BP, Market information in life cycle assessment. Miljøstyrelsen: (2003).

37. Tillman A-M, Significance of decision-making for LCA methodology. Environmental Impact Assessment Review 20(1):113-123 (2000).

38. Finnveden G, Hauschild MZ, Ekvall T, Guinée J, Heijungs R, Hellweg S, et al., Recent developments in Life Cycle Assessment. Journal of Environmental Management 91(1):1-21 (2009).

39. Singh A, Pant D, Korres NE, Nizami A-S, Prasad S and Murphy JD, Key issues in life cycle assessment of ethanol production from lignocellulosic biomass: challenges and perspectives. Bioresour. Technol. 101(13):5003-5012 (2010).

40. Luo L, van der Voet E, Huppes G and de Haes HAU, Allocation issues in LCA methodology: a case study of corn stover-based fuel ethanol. The International Journal of Life Cycle Assessment 14(6):529-539 (2009).

41. Ardente F and Cellura M, Economic Allocation in Life Cycle Assessment. Journal of Industrial Ecology 16(3):387-398 (2012).

42. Weidema BP, Ekvall T and Heijungs R, Guidelines for Consequential and Hybrid LCA. Deliverable D18 of work package 5 of the CALCAS project. Project no.037075, Co-ordination Action for innovation in Life-Cycle Analysis for Sustainability (2009).

43. Sandin G, Røyne F, Berlin J, Peters GM and Svanström M, Allocation in LCAs of biorefinery products: implications for results and decision-making. Journal of Cleaner Production DOI: 10.1016/j.jclepro.2015.01.013 (2015).

44. Wiloso EI, Heijungs R and de Snoo GR, LCA of second generation bioethanol: A review and some issues to be resolved for good LCA practice. Renewable and Sustainable Energy Reviews 16(7):5295-5308 (2012).

45. Mattila T, Helin T, Riina Antikainen, Soimakallio S, Pingoud K and Wessman H, Land use in life cycle assessment. The Finnish Environment 24/2011. Finnish Environment Institute, Helsinki (2011).

46. Mathews JA and Tan H, Biofuels and indirect land use change effects: the debate continues. Biofuels Bioproducts \& Biorefining-Biofpr 3(3):305-317 (2009).

47. Ahlgren S and Di Lucia L, Indirect land use changes of biofuel production - a review of modelling efforts and policy developments in the European Union. Biotechnology for Biofuels 7(1):35 (2014).

48. Finkbeiner M, Indirect land use change - Help beyond the hype? Biomass and Bioenergy 62(0):218-221 (2014).

49. Brandão M, Levasseur A, Kirschbaum MUF, Weidema BP, Cowie AL, Jorgensen SV, et al., Key issues and options in accounting for carbon sequestration and temporary storage in life cycle assessment and carbon footprinting. International Journal of Life Cycle Assessment 18(1):230-240 (2013).

50. International Organization for Standardization, ISO/TR 14047:2012, Environmental management -- Life cycle assessment -- Illustrative examples on how to apply ISO 14044 to impact assessment situations (2012).

51. Agostini A, Giuntoli J, Boulamanti A and Marelli L, Carbon accounting of forest bioenergy. Conclusions and recommendations from a critical literature review. JRC Technical Reports, Report EUR 25354 EN (2013). 
52. Peters GP, Aamaas B, T. Lund M, Solli C and Fuglestvedt JS, Alternative global warming metrics in life cycle assessment: a case study with existing transportation data. Environmental Science \& Technology 45(20):8633-8641 (2011).

53. Cherubini F, Peters GP, Berntsen T, Strømman AH and Hertwich E, $\mathrm{CO}_{2}$ emissions from biomass combustion for bioenergy: atmospheric decay and contribution to global warming. GCB Bioenergy 3(5):413-426 (2011).

54. Ericsson N, Porsö C, Ahlgren S, Nordberg A, Sundberg C and Hansson P-A, Time-dependent climate impact of a bioenergy system - methodology development and application to Swedish conditions. $G C B$ Bioenergy 5(5):580-590 (2013). 
Substitution: Comparing product A from different systems
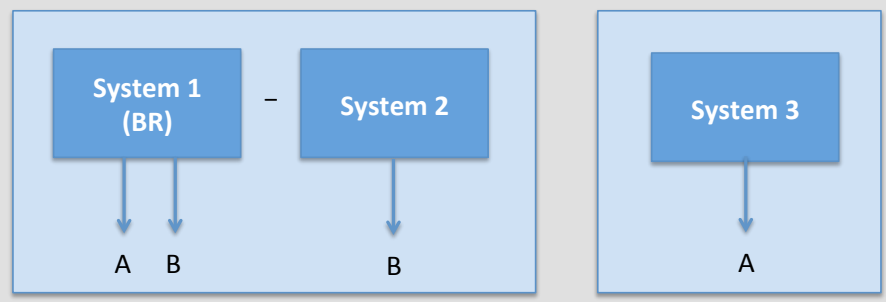

System enlargement: Comparing product A + B from different systems
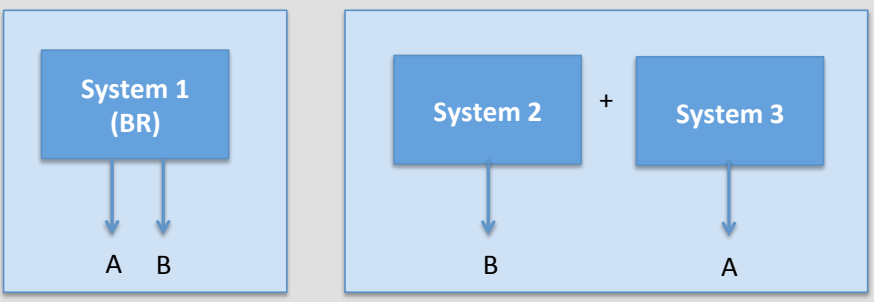

Figure 1. Illustration (inspired by Finnveden ${ }^{34}$ ) of two types of system expansion:

substitution and system enlargement. The substitution case compares product A, produced in system 1 or 3 . The system enlargement case compares product A plus product B from production system 1 or 2 and 3 . BR=biorefinery. 
Table 1. Standard and guidelines included in the review

\begin{tabular}{lll}
\hline $\begin{array}{l}\text { Reference } \\
\text { number }\end{array}$ & Standard/Guideline & Referred to in text \\
\hline 10 & $\begin{array}{l}\text { ISO 14040:2006, Environmental management - Life cycle assessment - } \\
\text { Principles and framework }\end{array}$ & ISO 14040 standard \\
11 & $\begin{array}{l}\text { ISO 14044:2006, Environmental management - Life cycle assessment - } \\
\text { Requirements and guidelines }\end{array}$ & ISO 14044 standard \\
12 & International Reference Life Cycle Data System (ILCD) & ILCD Handbook \\
13 & Greenhouse Gas Protocol. Product Life Cycle Accounting and Reporting & GHG Protocol \\
& Standard. & \\
14 & EU Product Environmental Footprint (PEF) & PEF \\
15 & EU Organisation Environmental Footprint (OEF) & OEF \\
16 & ISO 14025:2006, Environmental labels and declarations & ISO 14025 standard \\
17 & Product Category Rules PCR 2011:17: Basic organic chemicals & PCR \\
18 & Renewable Energy Directive (2009/28/EC, Article 19 and Annex V) & RED \\
19 & The European Committee for Standardization (CEN) EN 16214-4: & RED \\
& Sustainably produced biomass for energy applications ${ }^{\text {a }}$ & \\
20 & ISO/TS 14067: Carbon footprint of products - Requirements and & ISO/TS 14067 \\
& guidelines for quantification and communication &
\end{tabular}

${ }^{\mathrm{a}}$ Elaborates the calculation rules within the RED framework 
Table 2. Categories and examples of recommended functional units (FU) for studying different research questions in LCA studies of biorefinery (BR) systems

\begin{tabular}{|c|c|}
\hline Category and example of FU & Examples of research questions \\
\hline \multicolumn{2}{|l|}{ Use offeedstock } \\
\hline 1 hectare & $\begin{array}{l}\text { What is the best use of land? What are the consequences for the environment } \\
\text { of using land in different ways? }\end{array}$ \\
\hline 1 ton biomass & $\begin{array}{l}\text { What technological pathway is best for conversion of this biomass? What } \\
\text { are the environmental profiles of the different feedstock? }\end{array}$ \\
\hline $\begin{array}{l}\text { Waste treatment of } 1 \text { ton } \\
\text { municipal household waste }\end{array}$ & $\begin{array}{l}\text { What is the best waste treatment for this waste? What is the best use of } \\
\text { biomass waste? }\end{array}$ \\
\hline \multicolumn{2}{|l|}{ Single product } \\
\hline $\begin{array}{l}1 \mathrm{~kg} \text { product } \\
1 \mathrm{MJ} \text { product }\end{array}$ & What is the environmental impact of a BR product? What is the \\
\hline $\begin{array}{l}\text { Function of single product } \\
1 \text { MJ electricity } \\
1 \text { person-km }\end{array}$ & $\begin{array}{l}\text { environmental impact of increased demand for a BR product? How is the } \\
\text { environment affected by the use of a BR product? }\end{array}$ \\
\hline \multicolumn{2}{|l|}{ Multifunctional } \\
\hline 1 biorefinery & $\begin{array}{l}\text { What are the hotspots in the BR production system? What is the } \\
\text { environmental impact of the BR? What is the environmental impact of } \\
\text { building and running a new BR compared with business as usual? How is } \\
\text { the environment affected by the use of different feedstocks for the BR? }\end{array}$ \\
\hline $\begin{array}{l}\text { Combination of output } \\
\text { products }\end{array}$ & $\begin{array}{l}\text { What is the environmental impact from these BR products? What is the } \\
\text { optimal combination of output products for reducing environmental impact? } \\
\text { What is the environmental impact of process integration (i.e. BR vs. stand- } \\
\text { alone bioenergy production? }\end{array}$ \\
\hline
\end{tabular}

